\title{
DE LA PERIFÈRIA AL CENTRE: EL CAS DE FERDYDURKE DE WITOLD GOMBROWICZ
}

\author{
BOŻENA ANNA ZABOKLICKA ZAKWASKA \\ Universitat de Barcelona \\ bozena.zaboklicka@ub.edu
}

\section{RESUM}

Seguir les traces de la novel-la Ferdydurke de Gombrowicz des de Polònia, a través de l'Argentina, París fins a Catalunya i Espanya, permet mostrar els mecanismes que fan que una obra d'un autor desconegut que escriu en una llengua minoritària arribi a estar present en altres àmbits culturals. Gombrowicz, exiliat a l'Argentina durant la Segona Guerra Mundial, tradueix Ferdydurke al castellà amb l'ajut d'uns amics llatinoamericans. L'obra passa desapercebuda a l'Argentina, a causa de la indiferència de l'elit cultural del país.Com que el règim comunista a Polònia no permet publicar autors polonesos exiliats, Gombrowicz edita les seves obres a París en un important centre de la cultura polonesa que aconsegueix que Ferdydurke es publiqui en francès. A partir de l'èxit francès, l'obra és publicada a la majoria dels països d'Europa occidental. A Espanya la primera edició de la novel·la és en català (1968), mentre que l'espanyola no es fa fins al 1984. L'exemple d'aquesta obra, una de les més importants i universals de la literatura contemporània polonesa, demostra que la literatura creada en llengües minoritàries no té possibilitats d'èxit internacional si no és "descoberta" prèviament al país que dicti les modes literàries.

PARAULES CLAU: Ferdydurke, Gombrowicz, Ferrater, traducció, llengües minoritàries.

\section{FROM THE PERIPHERY TO THE CENTER: THE CASE OF FERDYDURKE OF WITOLD GOMBROWICZ}

\section{ABSTRACT}

Following the track of the novel Ferdydurke by Gombrowicz from Poland via Argentine and Paris to Catalonia and Spain shows the mechanisms that make it possible for a work of a little known author writing in a minority language to become present in other cultures.

Gombrowicz, an exile in Argentine during World War II, translated Ferdydurke into Spanish with the help of his Latin American friends but the novel went unnoticed there due to the lack of interest on the part of the country's cultural elite. Since the works of Polish authors in exile were banned by the communist regime in Poland, Gombrowicz, had first his books published by the influential Centre of Polish Culture in Paris, that brought about the translation of Ferdydurke into French and publication by a French publishing house. After the French success, the novel was published in most West European countries. In Spain, its first edition was in Catalan, whereas the Spanish version did not appear until 1984. The example of Ferdydurke, one of the most important and universal works of the Polish contemporary literature shows that books written in minority languages have little chance of becoming internationally successful unless they are previously "discovered" in the country that dictates literary fashions.

KEY WORDS: Ferdydurke, Gombrowicz, Ferrater, translation, minoritary languages. 
La història del llarg periple de Ferdydurke des de Varsòvia fins a Espanya demostra, per una banda, que sovint la nostra coneixença d'una important obra literària estrangera traduïda pot ser fruit d'un cúmul de circumstàncies afortunades i, per altra, prova que, sense una empenta des de la institució literària del centre que dicta les normes i les modes a la literatura mundial del moment, cap obra escrita en una llengua minoritària, no pot arribar a formar part del cànon literari internacional, per més important o innovadora que sigui.

Witold Gombrowicz (1904-1969) és un dels escriptors polonesos més coneguts i més apreciats al món i, cal afegir, és l'únic autor polonès l'obra completa del qual ha estat traduïda íntegrament al castellà i publicada a Espanya. Però el seu reconeixement internacional no va ser ni fàcil ni immediat.

Ferdydurke, la novel-la que es convertiria en l'obra més famosa de l'escriptor i alhora en l'exposició de la seva coneguda teoria de la forma, va ser el segon llibre que Gombrowicz havia publicat a Polònia l'any 1937. Ferdydurke tracta sobre els problemes existencials de l'individu dins de la societat, però al mateix temps és una obra literària innovadora que barreja la ficció amb l'assaig i la convenció realista amb elements fantasmagòrics i creacionistes. Dins del panorama literari polonès dels anys trenta, Ferdydurke va ser una obra innovadora i el seu autor va ser considerat el creador d'una prosa experimental, cosa que el va situar en el primer pla de la jove literatura polonesa.

Ferdydurke va aparèixer en un moment molt especial de la literatura polonesa, en els anys entre les dues guerres mundials (1918-1939), que van ser anys d'una veritable eclosió de la nova literatura. El 1918 Polònia va recuperar la independència després de 146 anys de falta de llibertat durant els quals la literatura havia estat totalment sotmesa als objectius patriòtics, identitaris i de supervivència nacional.

La situació de les lletres poloneses va canviar radicalment amb la recuperació de l'Estat propi. Mai abans ni després dels anys 1918-1939 no s'ha donat en la cultura polonesa una vida literària tan rica. Els anys d'entreguerres van ser a la història de la cultura polonesa una veritable excepció. I Gombrowicz és una de les figures literàries més creatives i innovadores d'aquest període.

L'1 d'agost de 1939 Gombrowicz, convidat a la travessia inaugural d'un transatlàntic que havia de cobrir el trajecte entre Polònia i l'Amèrica del Sud, va partir cap a Buenos Aires. El vaixell va arribar a l'Argentina el 20 d'agost i va abandonar el port del país de La Plata una setmana abans de l'esclat de la Segona Guerra Mundial. ${ }^{1}$ No obstant, ja no hi havia cap dubte que l'inici de la

\footnotetext{
${ }^{1}$ Fins al 2005 la versió sobre l'emigració de Gombrowicz va ser diferent. Es creia, pel que havia suggerit el mateix escriptor, que l'esclat de la Segona Guerra Mundial el va sorprendre en terra argentina i el va fer decidir no tornar a Europa, ja que era impossible arribar a la Polònia envaïda per les tropes nazis. No obstant, el 2005 es va publicar a Polònia la tesi doctoral de Klementyna Suchanow, que demostrava que Gombrowicz havia decidit quedar-se a Buenos
} 
guerra era qüestió de dies i davant de la perspectiva que el vaixell no pogués tornar a Polònia i es quedés pel camí, Gombrowicz va decidir quedar-se a Buenos Aires. El que havia de ser un viatge breu es convertiria en una estada a l'Argentina de gairebé vint-i-quatre anys. Gombrowicz, un escriptor jove però ja reconegut i prometedor, un crític literari l'opinió del qual comptava en els cercles literaris del país, d'un dia per a l'altre es va trobar exclòs per les circumstàncies històriques del seu món i de la seva llengua i llançat enmig d'un país desconegut per a ell i que ignorava del tot la seva existència com a home de lletres. Durant els primers anys de la seva estada a l'Argentina, Gombrowicz va subsistir molt modestament donant classes particulars de filosofia a mestresses de casa poloneses i més tard treballant com a empleat del Banc Polonès. En aquests anys va considerar el seu passat literari definitivament tancat i oblidat. Però el que no podia oblidar era el seu passat de rei dels cafès literaris i va començar a freqüentar el cafè Rex de Buenos Aires, on la seva personalitat provocativa i estrafolària de conde polaco, com es feia anomenar, no va trigar gaire a atreure joves artistes locals. I van ser justament aquests joves els que contribuirien al seu retorn a la literatura, ja que tots els intents d'establir contactes amb els cercles literaris argentins consolidats van resultar un fracàs. ${ }^{2}$

Precisament aquests joves amics van tenir molt a veure amb el destí i la fama mundial de Ferdydurke i del seu autor. L'any 1946 Gombrowicz es va trobar per enèsima vegada en una situació econòmica desesperant i se li va acudir una idea enginyosa per guanyar alguns diners. Va demanar a una amiga rica, Cecilia Debenedetti, que li financés la traducció de Ferdydurke a l'espanyol i es va reservar sis mesos per realitzar-la. El nivell del seu espanyol no li permetia enfrontar-se en solitari a aquesta tasca, així que Gombrowicz traduïa com podia fragments de l'obra i després els portava al cafè Rex, on els seus amics refeien amb ell frase per frase buscant paraules i girs adequats, lluitant amb la sintaxi i amb els neologismes dels quals l'obra està plena. L'equip que va intervenir en la traducció de Ferdydurke a vegades arribava a deu persones, de les quals les més importants van ser: Virgilio Piñera, Humberto Rodríguez Tomeu, tots dos escriptors cubans, i els argentins Adolfo de Obieta i Luis Centurión. ${ }^{3}$

Aires una setmana abans de l'inici de la guerra. Cfr. SUCHANOW, K. (2005). Argentyńskie przygody Gombrowicza, Kraków, WL, 5-30.

2 Sobre el fracàs en les relacions de Gombrowicz amb l'elit cultural de l'Argentina escriu Pau Freixa Terradas en el capítol "El fiasco de la temptativa Sur" de la seva tesi doctoral FREIXA, P. (2008), Recepció de l'obra de Witold Gombrowicz a l'Argentina i configuració de la seva imatge a l'imaginari cultural argentí, 43-49.

http://www.tdx.cat/bitstream/handle/10803/2093/PFT TESI.pdf?sequence=1

${ }^{3}$ La primera edició de la novel-la en castellà (editorial Argos, Buenos Aires, 1947) va anar precedida per un "Prefacio para la edición castellana" de l'autor i una "Nota sobre la Traducción" firmada por "Los Traductores". En el "Prefacio" Gombrowicz mencionava vint persones que en diverses ocasions van participar en la preparació de la versió castellana de l'obra. El nucli del Comité de traducció el constituïen quatre persones: dos cubans, Virgilio 
Com comenta el mateix Gombrowicz en el Diario (Gombrowicz 2005: 205207), va començar aquesta feina sense gaire convenciment, de fet només hi veia la utilitat econòmica, ja que li semblava que aquest llibre ja era mort per a ell. Però a mesura que el procés de la traducció anava progressant i gràcies a l'entusiasme dels seus joves col-laboradors, es va adonar que aquella obra podia tornar a viure entre el públic estranger, i que per tant, es tractava d'un llibre universal que podria fer carrera en qualsevol moment i a qualsevol lloc del món. A més, Gombrowicz, des de la seva posició privilegiada d'autor de l'obra va aprofitar la traducció per reescriure-la, introduint-hi canvis importants respecte l'original. ${ }^{4}$ Al "Prefacio para la edición castellana" l'escriptor deia: "Esta traducción fue efectuada por mi y solo de lejos se parece al texto original" (Gombrowicz 1947: 13), amb la qual cosa de fet reconeixia que el text que oferia als lectors de parla hispana era una segona versió de la novel·la publicada deu anys abans en polonès.

Ferdydurke va aparèixer publicada en castellà l'any 1947 per l'editorial Argos de Buenos Aires, en la col-lecció Obras de Ficción. No obstant, l'obra, encara que no va passar del tot desapercebuda a l'Argentina, no va començar la seva carrera internacional a Buenos Aires, on al cap i a la fi no era més que l'obra d'un desconegut escriptor estranger no avalat per la crítica de París. A més, es tractava d'un llibre que com diu el mateix Gombrowicz no complaïa ni el grup de la intel-lectualitat progressista argentina, que estava sota el signe de Marx i la lluita de classes i reclamava una literatura compromesa políticament, ni els que es delectaven amb les exquisideses de la cultura europea (Gombrowicz 2005: 207). Per si això fos poc, la novel-la anava precedida d'un prefaci del mateix autor, escrit com sempre amb un to provocatiu, en què Gombrowicz s'atrevia a parlar ni més ni menys que de la immaduresa cultural del continent llatinoamericà, que comparava amb la immaduresa del seu propi país.

Me atrevo a creer que en todo caso la publicación de Ferdydurke en la América Latina tiene su razón de ser. Existen varias analogías entre la situación espiritual de Polonia y la de este continente. Aquí como allá el problema de la inmadurez cultural es palpitante. Aquí como allá el mayor esfuerzo de la literatura se pierde en imitar las "maduras" literaturas extranjeras. Aquí y allá los literatos se preocupan por todo menos por verificar

Piñera i Humberto Rodríguez Tomeu i dos argentins, Luis Centurión i Adolfo de Obieta, però hi van colllaborar també: Jorge Calvetti, Manuel Claps, Carlos Coldaroli, Adán Hoszowski, Gustavo Kotkowski, Pablo Manen, Mauricio Ossorio, Eduardo Paciorkowski, Ernesto J. Plunkett, Luis Rocha, Alejandro Rússovich, Carlos Sandelín, Juan Seddon, José Taurel, Luis Tello i José Patricio Villafuerte.

${ }^{4}$ El canvi més important va ser la substitució de gairebé tot el capítol IV, "Filifor forrado de niño (Prefacio)", que representa la part cabdal de la novel-la en ser el capítol en què l'autor exposa la teoria de la forma que subjau a tota la seva obra (Zaboklicka 2002: 567-573 i Zaboklicka 2010: 87-99). Sobre la traducció de Ferdydurke al castellà escriu també Marcin Kurek en "Ferdydurke po hiszpańsku (kilka uwag o autorskim przekładzie Gombrowicza)" a SKIBIŃSKA, E. (2004), Gombrowicz i tłumacze, Łask, Leksem, 13-20. 
sus derechos a escribir como escriben. En Polonia como en Sudamérica todos prefieren lamentarse de su condición inferior de menores y peores, en vez de aceptarla como un nuevo y fecundo punto de partida. Pero mientras en Polonia la formidable tensión de la vida echa por tierra toda esa "escuela literaria" (la palabra "escuela" está aquí plenamente justificada), la apacible existencia del feliz sudamericano le permite eludir la revisión básica de esas cuestiones, le induce al cultivo de cominerías estéticas e intelectuales, y un esteril formalismo sofoca toda su expresión. Dudo mucho si mis razones serán compartidas por los maestros consagrados de ambas literaturas, pero fijo mis esperanzas en los maestros que están por nacer (Gombrowicz 1947: 12-13).

Totes les circumstàncies esmentades situaven l'obra en una posició desfavorable dins del sistema literari d'arribada, i en conseqüència la novel·la que en el sistema original havia ocupat una posició no central, però sí prou important, en el sistema d'arribada va quedar desplaçada a una posició marginal.

Però la publicació de Ferdydurke a l'Argentina va tenir una importància cabdal per a Gombrowicz en el sentit que li va fer creure que no estava acabat com a escriptor. L'èxit relatiu del llibre en un terreny tan allunyat del lloc on va ser creat i deu anys després de la primera edició va donar impuls a l'autor per continuar escrivint.

L'arribada, però, de l'obra de Gombrowicz al mercat europeu i, entre d'altres, a l'espanyol i al català no va ser a través de l'Argentina, sinó a través d'un important centre cultural i editorial polonès a l'exili.

Després de la Segona Guerra Mundial la situació de la literatura polonesa no va tornar a la normalitat, interrompuda per sis anys d'ocupació nazi. Acabada la guerra, d'acord amb les decisions del tractat de pau de Ialta, Polònia va caure dins l'òrbita de la influència soviètica i la seva literatura va ser convertida per decret en pur instrument propagandístic del nou sistema polític.

En aquesta situació molts escriptors polonesos, sobretot els que al final de la guerra es trobaven fora del territori polonès, van optar per l'exili. El seu problema més greu era la dispersió, ja que estaven disseminats per tots els continents. En aquestes circumstàncies, per a la supervivència de la cultura i de la literatura poloneses van tenir una importància cabdal tots els centres d'integració creats a l'exili.

La iniciativa cultural a l'exili més important, el paper de la qual és realment inestimable, va ser la fundació al començament de 1946, de l'editorial Instytut Literacki i més tard de la revista mensual Kultura a París. El seu fundador i director va ser Jerzy Giedroyc, un polític i veritable home-institució que durant més de quaranta anys va fer un gran servei a la cultura polonesa. ${ }^{5}$

\footnotetext{
${ }^{5}$ Sobre el paper de Jerzy Giedroyc i de la revista Kultura a la vida cultural polonesa durant el règim comunista hi ha extensa bibliografia en polonès, entre d'altes: POMIAN, K. (2000), W kręgu Giedroycia, Varsòvia, Czytelnik, BERBERYUSZ, E. (1995), Ksiażę z Maison-Laffitte, Gdańsk, Marabut o l'autobiografia del mateix redactor en cap de Kultura: GIEDROYC, J. (1996), Autobiografia na cztery ręce, Warszawa, Czytelnik (redacció de Krzysztof Pomian).
} 
Kultura va ser d'única tribuna lliure per als intel-lectuals i escriptors polonesos durant els anys del comunisme.

Giedroyc, que coneixia Gombrowicz d'abans de la guerra, es va posar en contacte amb ell per proposar-li colllaboracions. L'any 1951 la revista Kultura va publicar fragments de la següent novel-la de Gombrowicz, Transatlàntic, rebuts amb hostilitat per part dels polonesos a l'exili, que es van sentir agredits en la seva polonitat $\mathrm{i}$ en el seu patriotisme per una obra que atacava els estereotips nacionals. Malgrat això, Giedroyc, que estava disposat a arriscar-se per intentar canviar i modernitzar la consciència dels polonesos, va publicar Transatlàntic en forma de llibre el 1953. Al mateix temps va proposar a Gombrowicz que escrivís un diari per ser publicat per entregues a la revista Kultura. Així va començar la història del seu conegut Diari, publicat entre els anys 1953 i 1966, primer a la revista i desprès en forma de llibres. ${ }^{6}$ De manera que Gombrowicz era publicat en polonès, però no a Polònia, sinó a París. Va tornar a estar present en les revistes literàries poloneses a l'exili (no només a Kultura) i es va convertir en un dels autors més llegits, més controvertits i més universals de les lletres poloneses, encara que dins de Polònia el seu nom era totalment silenciat $i$, fora $d^{\prime}$ 'un estret cercle d'iniciats, era un autor del tot desconegut.

Al començament dels anys cinquanta es va organitzar a Berlín, amb suport americà, el Congrés per la Llibertat de la Cultura, presidit per Nikolai Nabokov, compositor i cosí de Vladimir Nabokov. Giedroyc va aconseguir introduir al Congrés un col-laborador seu, el crític literari més prestigiós de l'exili polonès, Konstanty Jeleński (Kot), que hi treballaria entre els anys 1952-1967 (Giedroyc 1996: 173-185).

El Congrés va ajudar a llançar a la fama mundial el futur premi Nobel de literatura, Czesław Miłosz (Glondys 2011: 120-149) i, encara que indirectament, també va contribuir a l'èxit de Gombrowicz, ja que dins del seu àmbit Giedroyc i Jeleński van conèixer François Bondy, escriptor, periodista, creador i redactor en cap de la prestigiosa revista cultural francesa Preuves (1951-1969). Jeleński, que es va convertir en col-laborador fix de Preuves (1953-1969), va fer que Bondy s'interessés per Gombrowicz (Giedroyc 1996: 176). Bondy és l'autor del primer article sobre Gombrowicz, "Notes sur Ferdydurke", que es va publicar a França (Preuves, núm. 32, octubre de 1953) i que va incitar Maurice Nadeau, editor de Julliard, a publicar la novel-la que anteriorment havia rebutjat, igual que d'altres grans editors parisencs. Així que la primera edició europea de Ferdydurke (fora de Polònia) va ser la de l'editorial Julliard, que la va publicar en la col-lecció Les Lettres Nouvelles, a París, l'any 1958.

Una mica abans d'aquesta primera edició estrangera a Europa, a Polònia es va viure un breu període de desglaç (1956-1957) que va permetre una

\footnotetext{
${ }^{6}$ En vida de l'autor es van publicar a l'editorial Instytut Literacki de París tres volums del Diari corresponents als anys 1953-1956, 1957-1961 i 1961-1966. En les edicions posteriors a la mort de l'autor, el tercer volum va ser ampliat amb els textos publicats a Kultura després de l'aparició del tercer volum.
} 
passatgera tornada de Ferdydurke al seu país natal. Veiem, per tant, que Ferdydurke es va publicar a Polònia i a França més o menys al mateix temps. A Polònia es va fer càrrec de la nova edició la més prestigiosa editorial estatal: Państwowy Instytut Wydawniczy (Varsòvia, 1957).

Ara bé, l'èxit de Ferdydurke a París, encara que limitat a determinats cercles del país, li va obrir les portes d'altres editorials tant a França com a la resta d'Europa. Als anys seixanta els llibres traduïts, publicats i reconeguts a França rebien automàticament el passaport per a altres països, encara que la seva col-locació dins del sistema literari francès no fos central, com era el cas de Ferdydurke, obra innovadora i minoritària, malgrat els anys passats des de la seva creació. No obstant això, gràcies al reconeixement de la crítica francesa, Ferdydurke es va publicar al començament dels anys seixanta a tot Europa, menys a Espanya i als països de l'Est (a excepció de Polònia, com ja s'ha dit). A l'edició francesa la va seguir l'alemanya (1960), l'anglesa (i també l'americana el mateix 1961), la italiana (1961), l'holandesa (1962) i la reedició a l'Argentina, l'any 1964, per l'Editorial Sudamericana (Ryll, Wilgat 1972: 61-62, Gombrowicz: 2010: 805-834).

L'edició de la novel·la per Sudamericana amb pròleg d'Ernesto Sábato va suposar un veritable "descobriment" de Gombrowicz com a escriptor a la seva pàtria d'adopció. El reconeixement de l'escriptor a l'Argentina es produïa onze anys després de la publicació del llibre en castellà a Buenos Aires, quan els crítics francesos el van declarar una de les figures més importants de la literatura universal del segle XX.

Les notícies sobre Gombrowicz i Ferdydurke devien arribar a Espanya més o menys simultàniament des de l'Argentina i des de França. L'Espanya dels anys seixanta, per la seva situació política de país governat per una dictadura militar i nacionalcatòlica, temorosa d'influències de lliurepensadors estrangers i protegida per una doble censura, no era un lloc ideal per publicar literatura innovadora i avantguardista. Per aquests anys els llibres mal vistos pel règim arribaven d'amagat o des de França o justament des de l'Argentina. El cas és que d'entrada Ferdydurke no es va publicar en castellà a Espanya, però sí que hi va arribar l'edició de l'Editorial Sudamericana, i la novel·la va circular entre alguns integrants de l'elit intel·lectual del país. ${ }^{7}$ La primera edició que es va fer a Espanya va ser en català, amb una traducció a càrrec del novel-lista i prolífic traductor Ramon Folch i Camarasa, realitzada a partir de la traducció castellana

\footnotetext{
${ }^{7}$ A Espanya Ferdydurke va ser publicada per primera vegada en castellà per Edhasa el 1984. Malauradament, l'edició no era completa, ja que l'editorial va prescindir del "Prefaci" de l'autor i de la "Nota dels traductors" que formaven part íntegra de la versió castellana de la novel·la realitzada per Gombrowicz i els seus col-laboradors. A la pàgina de drets de l'edició de l'Edhasa tampoc figura la informació sobre l'autoria de la traducció, de manera que el lector s'assabenta només a través del "Pròleg" de Sábato que aquesta és obra de "un grupo de creyentes" (Sábato 1984: 8).
} 
amb l'autorització del mateix Gombrowicz. La va publicar a Barcelona Edicions 62 (col·lecció El balancí) l'any 1968 i el llibre es va reeditar l'any següent.

Eren anys en què la dictadura començava a suavitzar-se, obligada per raons econòmiques a obrir-se a Europa i els Estats Units. El turisme estranger que arribava massivament a Espanya i la proximitat de França (sobretot per als catalans) van fer que la censura cada vegada tingués menys sentit, ja que els llibres arribaven a Espanya amb l'intercanvi de gent, situació que ja va resultar impossible d'aturar.

El mateix any en què es va publicar Ferdydurke en català, a Espanya apareixia la traducció castellana de la novel·la Pornografia, titulada per qüestions de censura La seducción. L'obra es va publicar a Seix Barral (Barcelona, 1968) en traducció de Gabriel Ferrater, introductor de Gombrowicz a Espanya i autor del primer article sobre l'escriptor polonès, publicat a la revista Presencia (núm. 39, 15 de març de 1966). En aquest article, titulat Witold Gombrowicz, Ferrarter no només considerava Gombrowicz "el mayor prosista de hoy", sinó que també asseverava que "fue uno de los más notables escritores de la lengua española" (Ferrater 1986: 192). El seu entusiasme per l'obra de l'autor polonès el va portar fins i tot a intentar aprendre el polonès i a escampar la llegenda que la traducció de Pornografia s'havia realitzat directament de l'original. Llegenda que, per cert, continua viva, ja que a l'última edició de Pornografia (Seix Barral, 2002) apareix la informació que es tracta d'una traducció del polonès. No obstant, avui, gràcies a la investigació de Zofia Stasiakiewicz, que ha publicat la correspondència inèdita entre Ferrater i Gombrowicz, ha quedat demostrat que, malgrat l'intent d'aprendre la llengua de l'original, Ferrater va fer la seva traducció a partir de les versions francesa i alemanya (Stasiakiewicz 2012: 3139). S'ha de reconèixer, però, que, gràcies a l'entusiasme del poeta català, la majoria de les obres de Gombrowicz es van publicar a Espanya a finals dels anys seixanta i al començament dels setanta, quan la presència de la literatura polonesa als sistemes literaris espanyol i català era purament testimonial. ${ }^{8}$

El 1998, l'editor de Quaderns Crema, que coneixia la història de la versió argentina de Ferdydurke i de la seva fidel traducció catalana, va decidir editar una nova traducció al català, que van realitzar Anna Rubió i Jerzy Sławomirski, aquesta vegada a partir de l'original polonès. S'hi han respectat els canvis efectuats per l'autor en l'edició polonesa de 1957 (fets a partir de la traducció al castellà), canvis que l'autor va exigir explícitament a l'editorial polonesa.

Els diferents contextos on es van realitzar i publicar les dues traduccions al català (la primera el 1968 a partir de la "versió lliure" castellana del mateix autor i la segona realitzada directament del polonès, respectuosa amb

\footnotetext{
${ }^{8}$ Ferrater va tenir també un paper important en el reconeixement internacional de l'obra de Gombrowicz, ja que com a membre de la delegació espanyola en el jurat que atorgava anualment el Premi Internacional de Literatura del Grup Formentor, va defensar amb fermesa la candidatura de Gombrowicz en dues ocasions i va aconseguir que el 1967 l'autor fos guardonat amb el premi per la novel·la Cosmos.
} 
l'exotisme i sobretot amb l'extraordinària forma "visible" de l'original) fan que de fet estem davant de dues novel-les diferents.

La publicació de la segona traducció de Ferdydurke al català, que va posar de manifest l'existència de dues novel-les diferents del mateix autor i amb el mateix títol, va suscitar l'interès dels editors per repetir el mateix fenomen en castellà. El 2001 Seix Barral publicava la versió argentina de la novel·la i el 2005 l'editorial Galaxia Gutenberg/Círculo de Lectores treia una traducció nova directament del polonès realitzada pel mateix tàndem de traductors que havia fet la segona traducció al català. A partir del 2005, doncs, tant en català com en castellà es poden llegir dues Ferdydurke diferents, cosa que demostra la rellevància de l'obra de Gombrowicz.

L'arribada de Ferdydurke al públic internacional i, per tant, també al català i a l'espanyol, es deu, com ja s'ha dit, a un cúmul de felices circumstàncies. Entre aquestes circumstàncies cal esmentar en primer lloc el fet que Gombrowicz va quedar fora de Polònia durant i desprès de la guerra i que va decidir traduir la novel·la al castellà, llengua molt més accessible que el polonès i que permetia la seva lectura a França i arreu del món. ${ }^{9}$ L'altra feliç circumstància va ser l'interès per part de l'important centre cultural polonès a l'exili de propagar l'escriptor que ocupava un lloc important en el sistema literari polonès, encara que estigués rebutjat per la institució literària del país sota el règim comunista.

Veiem, doncs, com l'obra de Gombrowicz va arribar a Espanya a través de França per una banda (d'aquí venien les notícies sobre l'escriptor polonès i les crítiques entusiastes de les seves obres) i alhora des de l'Argentina. Totes les obres de Gombrowicz publicades a Espanya en aquella època es van publicar a Barcelona, que als anys seixanta i setanta també era el centre més important de la vida editorial a l'Estat per la seva proximitat amb França i amb Europa, d'on arribaven tota mena de novetats artístiques i intel-lectuals.

Totes les traduccions fetes a Espanya, tant al castellà com al català, van aparèixer en editorials i col-leccions prestigioses destinades als clàssics de la literatura moderna. La profusió de traduccions, als anys seixanta i setanta, obeïa al moment de crisi del sistema literari espanyol, afeblit per la situació política i el llarg període d'aïllament. Van ser anys en què es publicaven moltes traduccions de grans obres literàries estrangeres $i$ hi havia un visible interès per les literatures fins aleshores desconegudes com la polonesa, que aportaven nous valors i una nova visió del món provinents de darrere del "teló d'acer". El lector espanyol, sotmès durant els anys de la dictadura franquista a un dejuni

\footnotetext{
${ }^{9}$ Val la pena recordar que la versió castellana de Ferdydurke del mateix autor va servir de model per a la traducció al francès que va realitzar Gombrowicz amb un jove escriptor i periodista francès, Roland Martin. La traducció es va publicar a Julliard el 1958 sota el pseudònim de Brone. Al seu torn, de la traducció francesa es van realitzar traduccions a diverses llengües. Per tant, la Ferdydurke argentina va ser el punt de partida per a les traduccions al francès, anglès, italià, català, noruec i suec.
} 
intel-lectual forçós, es va llançar a conèixer les literatures fins aleshores absents al mercat nacional, i la demanda de novetats anava creixent juntament amb l'obertura política. La interferència literària es produïa acompanyada d'interferències en altres àmbits: turístic, comercial, polític.

L'obra de Gombrowicz és un exemple del fenomen d'interferència literària, que en el cas de Ferdydurke podríem qualificar d'indirecta, ja que l'obra va arribar a Espanya no directament des del país d'origen de l'autor, sinó precedida per l'anomenada que es va guanyar a França i en la versió castellana feta a l'Argentina.

En el sistema literari espanyol, l'obra de Gombrowicz, tot i que no tingui una situació central, hi és present sempre a partir del moment en què apareix l'edició de Pornografia (La seducción). Gombrowicz, que no deixa de ser un escriptor innovador fins i tot avui dia, alhora és considerat ja un clàssic modern i com a tal clàssic hi és sempre present en el mercat llibreter d'Espanya i de Catalunya.

El que és indubtable és que l'obra de Gombrowicz va arribar al sistema literari espanyol per interès d'un escriptor català, Gabriel Ferrater, i a través del sistema literari de Catalunya, que va ser el primer a incorporar l'obra de referència de l'escriptor, Ferdydurke, i va fer el paper d'intermediari entre el poderós sistema literari francès i l'espanyol.

\section{BIBLIOGRAFIA}

FERRATER, G. (1986), “Witold Gombrowicz", Papers, cartes, paraules, Barcelona, Quaderns Crema, 192-194.

FreIXA, P. (2008), Recepció de l'obra de Witold Gombrowicz a l'Argentina i configuració de la seva imatge a l'imaginari cultural argentí. [Consulta: 16.11.2012]. Disponible a: http://www.tdx.cat/bitstream/handle/10803/2093/PFT_TESI.pdf?sequence=1

GIEDROYC, J. (1996), Autobiografia na cztery ręce, Varsòvia, Czytelnik, 173-185

GLONDYS, O. (2011), “Kongres Wolności Kultury i wolność Czesława Miłosza: refleksja o zaangażowaniu i drodze do prawdy w dobie zimnej wojny", Archiwum Emigracji. Sztudia - Szkice - Dokumenty, Zeszyt 1-2 (14-15), 120-149.

GOMBROWICZ, R. (2010), "Wybór przekładów utworów Witolda Gombrowicza", Jarzębski J. (ed.), Witold Gombrowicz nasz wspótczesny, Kraków, Universitas, 805834.

GOMBROWICZ, W. (1947), Ferdydurke, (Traducido por el autor, asesorado por un Comité de traducción), Buenos Aires, Argos.

Gombrowicz, W. (2005), Diario (1953-1969), (trad. de Zaboklicka, B. i Miravitlles, F.), Barcelona, Seix Barral.

KUREK, M. (2004), “Ferdydurke po hiszpańsku (kilka uwag o autorskim przekładzie Gombrowicza)" a Skibińska E. Gombrowicz i tłumacze, Łask, Leksem, 13-20.

POMIAN, K. (2000) W kręgu Giedroycia, Varsovia, Czytelnik.

RYLL, L. WILGAT, J. (1972), Polska literatura w przekładach 1945-1970, Varsòvia, Agencja Autorska, 61-62. 
SÁBATO, E. (1984), "Prefacio a la edición argentina", Gombrowicz W. Ferdydurke, Barcelona: Edhasa, 7-13.

StASIAKIEWICZ, Z. (2012), Entre Catalunya i Polònia: Witold Gombrowicz i Gabriel Ferrater. Correspondència inèdita (1965-1967). Màster en Iniciació a la Recerca en Humanitats. [Consulta: 8 novembre 2012]. Disponible a: http://dugidoc.udg.edu/bitstream/handle/10256/7173/Tesina_master_Zofia_Stasiakiewicz.pd f? sequence $=1$

SuCHANOW, K. (2005), Argentyńskie przygody Gombrowicza, Kraków, WL, 5-30.

ZABOKLICKA, B. (2002), "Ferdydurke de Witold Gombrowicz en España: ¿traducciones o versiones?", Presa González F. (ed.), España y el mundo eslavo. Relaciones culturales, literarias y lingüísticas, Madrid, Gram Ediciones, 567-573.

ZABOKLICKA, B. (2010), „Ferdydurke w Katalonii: dwa przekłady, dwie różne powieści”, JARZĘBSKI, J. (ed.), Witold Gombrowicz nasz współczesny, Kraków, Universitas, 8799. 